\title{
A EDUCAÇÃO POPULAR NA PRÁXIS DA FORMAÇÃO PARA O SUS
}

\author{
POPULAR EDUCATION IN THE PRACTICE OF TRAINING FOR SUS
}

Juliana Acosta Santorum $^{1}$
Maria Elisabeth Cestari $^{2}$

Resumo Este trabalho é um estudo de caso que investigou em profundidade uma prática pedagógica de educação popular em saúde. Essa prática visou contribuir com mudanças na formação para o Sistema Único de Saúde (SUS), posto que, mesmo havendo avanços na saúde pública brasileira, ainda há muito a progredir para que os princípios e diretrizes do SUS se materializem nas práticas de atenção, gestão e educação no setor saúde. A observação participante foi o método utilizado para a produção de dados; também se configuraram em dados para a pesquisa os documentos referentes à organização e ao desenvolvimento do curso e os materiais produzidos no seu decorrer pelos sujeitos participantes. Todo o material produzido foi analisado na perspectiva da hermenêutica-dialética, e o referencial teórico utilizado para a análise da experiência foi o de Paulo Freire. A práxis investigada foi o curso de extensão universitária "Saúde, educação e política: práxis no SUS", desenvolvido na Universidade Federal do Rio Grande no ano de 2009. A amorosidade, a dialogicidade e a esperança foram, entre outros, os elementos da educação popular que caracterizaram essa prática educativa, que não se colocou neutra na formação dos estudantes, mas sim esteve marcadamente a favor da formação universitária crítico-reflexiva para que se atenda aos interesses da população na busca da consolidação do direito à saúde pública de qualidade.

Palavras-chave Sistema Único de Saúde; educação popular; educação em saúde.
Abstract This is an in-depth case study that investigated a popular health education practice. This practice sought to contribute to changes in training for the Unified Health System (SUS), since, despite the advances made in public health in Brazil, there is still much progress to be made in order for SUS' principles and guidelines to materialize in care, management and education practices in the health sector. Participant observation was the method used to produce data; documents relating to the organization and development of the course and materials produced by the participating subjects in their course were also used as a source of information. All of the material that was produced was analyzed from the hermeneutics-dialectics perspective, and the theoretical framework used to analyze the experience was that of Paulo Freire. The practice investigated was the continuing education course titled "Health, education and politics: the SUS practice," offered by the Rio Grande Federal University in 2009. Loveliness, dialogue and hope, among others, were the elements of popular education that characterized this educational practice, which did not remain neutral in training the students, but was markedly in favor of a critical-reflective university education designed to meet the interests of the population in the pursuit of consolidating the right to quality public health.

Keywords Unified Health System; popular education; health education. 


\section{Introdução}

Na década de 1970, a população brasileira, juntamente com trabalhadores do setor da saúde (da assistência, gestão e educação), organizou-se reivindicando um sistema de saúde que melhor atendesse às necessidades dos cidadãos que viviam (e ainda vivem) em diferentes realidades sociais. Desse movimento, chamado Reforma Sanitária Brasileira, originou-se o Sistema Único de Saúde (SUS), instituído pela Constituição Federal de 1988, que tem como princípios a integralidade, a universalidade e a equidade (Paim, 2009). Desde então, a formação de profissionais da saúde, a fim de se alcançar a concretização dos princípios e diretrizes do SUS, tem sido pensada, discutida e reformulada. Ainda assim, há muito a progredir.

De que forma é possível promover a apreensão e a internalização dos valores presentes na proposta do SUS? Como trabalhar pautando-se nas perspectivas de promoção da saúde, de integralidade da assistência e da participação popular no SUS? Como superar a formação puramente técnica e propiciar uma formação que leve o futuro trabalhador e a futura trabalhadora a refletirem sobre aqueles fatores que vão além das alterações fisiopatológicas que afetam o processo saúde-doença?

Mesmo enfrentando dificuldades - e às vezes contradições - na própria prática, os gestores do SUS, bem como as instituições de ensino, propõem projetos e programas para reorientar a formação e a pós-formação em saúde visando a transformações significativas nos serviços públicos de saúde. No entanto, os próprios gestores reconhecem as dificuldades na implementação das mudanças, afirmando que as propostas

(...) têm de enfrentar, em suas próprias concepções e desenvolvimentos, o desafio de constituírem-se em eixo transformador, em estratégias mobilizadoras de recursos e poderes, em recursos estruturantes do fortalecimento do SUS, deixando de estar limitadas a introduzir mudanças pontuais nos modelos hegemônicos de formação e cuidado à saúde (Brasil, 2003, p. 3).

Nesse sentido, foi desenvolvida no ano de 2009, na Universidade Federal do Rio Grande, uma prática pedagógica cuja intenção era contribuir para a efetivação do SUS e para uma formação universitária crítica, mas sem pretender obter respostas totalizadoras para os questionamentos que lhe deram origem. Inicialmente, elaborou-se uma proposta de disciplina optativa para a Escola de Enfermagem (EEnf/Furg), na qual poderiam matricular-se também os estudantes de cursos de graduação das ciências da saúde, sociais e humanas. Porém, naquele momento, o grupo de professores e estudantes que compunham o conselho da Escola de Enfermagem julgou não ser oportuno o acréscimo de disciplinas no currículo da Enfermagem - currículo 
que estava em processo de transição. Assim, a proposta da disciplina optativa foi modificada para a proposta de realização do curso de extensão universitária "Saúde, educação e política: práxis no SUS", nos moldes de uma disciplina experimental, a fim de que, futuramente, fosse repensada a sua introdução na grade curricular.

A intencionalidade dessa proposta foi permitir que estudantes oriundos de diferentes cursos de graduação vivenciassem o cotidiano de trabalho no setor da saúde pública e entrassem em contato com usuários do SUS no ambiente em que viviam, a fim de que pudessem organizar e desenvolver atividades a favor da efetivação do SUS.

Este artigo divulga parte dos resultados apreendidos no fazer da pesquisa. Acreditando que a educação popular na formação universitária contribui para a consolidação do SUS, este estudo teve como objetivo principal investigar em profundidade o desenvolvimento do curso de extensão universitária mencionado, buscando responder às seguintes questões iniciais: Como se deu o processo de ensino-aprendizagem no curso? De que forma a dialogicidade, a conscientização e a esperança foram abordadas/praticadas? Quais as potencialidades e as dificuldades dessa práxis? Do ponto de vista dos/as estudantes, quais são os significados dessa vivência no que diz respeito à sua formação?

\section{Percurso metodológico}

Esta pesquisa é um estudo de caso com abordagem qualitativa e exploratória dos dados. O estudo de caso é um método ideal quando o "pesquisador quiser entender um caso particular levando em conta seu contexto e complexidade" (André, 2008, p. 29). É característico desse método o fato de possuir limites bem definidos, pautados pelos objetivos da pesquisa. Mesmo que parecido com outros casos, cada estudo é único, e sua singularidade se expressa por possuir interesses próprios. "Os estudos de caso buscam retratar a realidade de forma completa e profunda" dentro daquilo a que se propõem. Para isso, "usam uma variedade de fontes de informação" (Lüdke e André, 1986, p. 19).

O caso em questão envolve o desenvolvimento de um curso de extensão universitária em caráter de disciplina optativa, fundamentado na educação popular em saúde, realizado em uma universidade pública. Os dados foram produzidos por meio da observação participante, realizada durante os três meses de desenvolvimento do curso. Também configuraram dados para análise os documentos referentes à organização e ao desenvolvimento do curso, além dos materiais produzidos no seu decorrer pelos sujeitos participantes (narrativas, relatórios, avaliações processuais e texto final de avaliação). 
A observação participante permite maior compreensão da rede de significados de determinados comportamentos por meio da escuta atenta de discursos e observação de atitudes, pois "conduz à apreensão de uma totalidade integrada de significados, nos níveis consciente e inconsciente, por parte da mente do observador" (Turato, 2003 p. 285).

O diário de campo se caracteriza como o instrumento para o registro das observações; é o momento de produção e de documentação dos dados da pesquisa, permitindo "transformar as relações estudadas em textos que constituem as bases para as análises efetivas" (Flick, 2009, p. 265). Assim, sistematicamente, do primeiro ao último dia do curso, logo após cada período observado, o conteúdo das observações foi registrado, tomando-se por base as anotações de campo, que se transformaram em relatos descritivos e reflexivos no diário de campo.

A análise dos dados foi iniciada no transcorrer da pesquisa, pela necessidade de avaliar o seu desenvolvimento e identificar as situações vivenciadas pelos sujeitos envolvidos. Ao final da etapa de produção dos dados - período que compreendeu os três meses de desenvolvimento do curso -, realizaramse várias leituras dos dados para que, então, fosse possível sistematizá-los e interpretá-los.

A análise final foi orientada pela hermenêutica-dialética, método que permite relacionar as situações vivenciadas em um dado momento com o contexto mais amplo. Assim, buscou-se descrever e analisar o processo educativo compreendendo-se as dificuldades e potencialidades da práxis e situando os dados produzidos em seu contexto. A hermenêutica-dialética permite o aprofundamento na análise dos dados e a interpretação da interação social com base em um referencial teórico (Minayo, 2004), tendo sido escolhida como suporte para o trabalho a obra de Paulo Freire.

Participaram da pesquisa 15 estudantes de Enfermagem, 2 de Psicologia, 1 de Educação Física, 1 de Fisioterapia e 1 de Biblioteconomia, todos eles inscritos no curso. Entre os indivíduos envolvidos na organização e na execução da atividade, estão dois professores do curso de Enfermagem, um estudante do mestrado em Enfermagem, um do mestrado em Ciências da Saúde, um do doutorado em Educação Ambiental e um da especialização em Abordagem Multidisciplinar em Dependência Química. Como dos 26 sujeitos apenas dois eram do sexo masculino, toda vez que nos reportarmos a eles, usaremos o gênero feminino, mantendo assim o anonimato. Os/as estudantes estão representados/as pela letra E seguida por uma sequência numérica: E1, E2, E3, ...; as organizadoras, pela letra O, seguida também de uma sequência numérica: $\mathrm{O} 1, \mathrm{O} 2, \mathrm{O} 3 \ldots$

Os sujeitos receberam um Termo de Consentimento Livre e Esclarecido que torna explícitas as intenções e os processos da pesquisa. O presente trabalho segue as diretrizes e normas regulamentadoras de pesquisas envol- 
vendo seres humanos segundo a resolução n. 196/1996 do Conselho Nacional de Saúde. O estudo foi aprovado pelo Comitê de Ética em Pesquisa na Área da Saúde (Cepas), da Universidade Federal do Rio Grande, no parecer n. $82 / 2009$.

No processo de análise, os dados produzidos ao longo da pesquisa foram lidos atenta e repetidamente, buscando-se responder às questões iniciais que balizaram as observações. Assim, à medida que forem relatados aspectos da prática educativa investigada, serão também analisadas, com base no referencial teórico, as suas características. Dessa forma, os dados são apresentados não como uma forma de teorizar sobre a prática da educação popular e a saúde, mas sim de teorizar a partir de uma prática. Também não é apenas uma reflexão ou simples especulação, mas um esforço de abstração dos fatos para analisar seus sentidos, buscando atingir o objetivo da pesquisa e alcançar uma visão crítica, política, histórica e socialmente situada sobre o fenômeno estudado.

\section{Resultados e discussão}

A educação popular é uma prática pedagógica que visa ao desenvolvimento da tomada de consciência, contribuindo tanto para a transição da consciência ingênua para a consciência crítica quanto para a conscientização da práxis dos sujeitos. A práxis pode ser entendida como uma ação política e transformadora na qual teoria e prática representam polos inseparáveis. Assim, a práxis é, ao mesmo tempo, objetiva - pois age em uma instância real - e subjetiva - pois primeiro acontece na consciência dos indivíduos (Batista, 2007).

Paulo Freire foi o grande fundamentador da educação popular. Ele próprio afirmava não existir um método prescritivo a ser seguido, mas sim certos princípios direcionadores, entre os quais: saber ouvir, desmontar a visão mágica, aprender/estar com o outro, assumir a ingenuidade dos educandos e viver pacientemente impaciente (Ceccim, 2007). Outros princípios se desdobram desses, como a dialogicidade e a politicidade da educação, a necessidade de correr riscos e reinventar as coisas, de reconhecer que ninguém está só no mundo e de que é preciso amor ao que se faz, amor às pessoas e amor às causas nas quais nos engajamos esperançosamente (Freire, 2006).

A amorosidade, que é expressão do bem-querer ao outro e à própria prática, é uma das características que marcaram o curso. Afinal,

como ser educador, se não desenvolvo em mim a indispensável amorosidade aos educandos com quem me comprometo e ao próprio processo formador de que sou parte? Não posso desgostar do que faço sob pena de não fazê-lo bem (Freire, 2006, p. 40). 
A amorosidade pôde ser percebida não só no afeto manifestado entre os participantes, mas no cuidado com o ambiente e na dedicação e no empenho de todos para fazer do curso uma prática educativa prazerosa.

A proposta de desenvolver o curso aos sábados pela manhã veio dos/as próprios/as estudantes interessados/as, pois o montante de atividades curriculares que desenvolviam inviabilizava a participação da maioria no curso. A princípio as organizadoras, considerando o dia e o horário, ficaram temerosas de que poucas pessoas se interessassem pela atividade, ou de que, com o passar do tempo, a presença diminuísse, mas houve grande procura e foi preciso aumentar o número de vagas oferecidas. Além disso, em nenhuma aula dos três meses de curso, mesmo com um período de chuvas intensas e um semestre letivo curto por causa do prolongamento das férias em decorrência da gripe $\mathrm{A}-\mathrm{e}$, por isso, um semestre intenso e concentrado -, estiveram ausentes mais da metade das inscritas. Isso demonstra o envolvimento com a proposta, o querer bem à prática.

A amorosidade tem justa relação com o comprometimento do educador e da educadora com a alegria de viver, com o querer bem ao educando e à própria prática educativa, o que não significa docilidade ingênua, mansidão imobilizadora ou o favorecimento aos que se tem maior afetividade (Freire, 2006). A amorosidade é uma afirmação ética de posicionamentos assumidos diante do mundo, pois é quando deixamos explícitas as causas pelas quais lutamos e também pelas quais não nos juntamos. O amor à causa é imprescindível às lutas, é o que move homens e mulheres que se engajam na busca por um mundo melhor.

Revelando a coerência metodológica com que foi conduzido o curso, as avaliações processuais foram uma das formas de expressão da dialogicidade. Por meio delas, os/as estudantes foram levados/as a refletir sobre a prática, a fim de reorientá-la, e foram situados/as como protagonistas, como sujeitos fundamentais na construção do espaço de ensino-aprendizagem. As avaliações levaram ao pensar sobre a prática que vivenciavam e construíam, e também à reflexão sobre as próprias posturas nessa prática, a exemplo do que narra uma estudante, nesta fala:

Confesso que no início do curso não era tão participativa, por achar que, pelo fato de estar no segundo semestre [do curso de graduação], minha participação não seria de grande importância. Porém, no dia da dinâmica, que serviu como uma autoavaliação, pude ver o quanto estava enganada, e a partir desse dia mudei minhas atitudes no curso. Certamente sem essa dinâmica não teria notado que minha participação é muito válida, pois quando expomos nossa opinião, o entendimento sobre o que está sendo discutido torna-se mais fácil (E12, Reflexão final, 11 dez. 2009). 
O diálogo foi praticado em uma relação horizontal, não como uma técnica em que todos têm de falar, e sim como metodologia de uma prática na qual todos têm direito à palavra, que não é somente o meio pelo qual se desenvolve o diálogo, mas que é constituída de ação-reflexão fundada no amor e na humildade, comprometida com a transformação do mundo (Freire, 2005).

Nessa práxis, alguns reaprenderam que o ensinar mediante o diálogo é estabelecer uma conexão entre sujeitos ensinantes e sujeitos aprendentes que implica ouvir o outro e respeitar seus saberes, é uma reflexão conjunta sobre o objeto de conhecimento (Freire e Shor, 1987). Assim, aqueles que já tinham algum conhecimento sobre o assunto, puderam re-conhecer o que já era sabido, ou seja, passaram a conhecer melhor a partir do momento em que conheceram de novo, sob outra ótica e em outro contexto:

Apesar de já ter tido aula sobre o Sistema Único de Saúde e as políticas públicas de saúde, hoje consigo ter outras interpretações sobre o assunto. Antes, quando tive a explanação, estava na fase inicial da faculdade e minha visão era a de usuária que desconhecia a história, achava o sistema ruim, uma utopia teórica. (E4, Narrativa, 7 nov. 2009).

Nesse momento, E4 cursava a $7^{a}$ série da graduação em Enfermagem e referiu-se ao SUS apenas como um conteúdo visto no início do curso - o que também é confirmado por outros/as estudantes da área da saúde. Como é possível que, ao chegarem ao final de um curso de graduação que tem suas aulas práticas e estágios nos serviços públicos, vejam o Sistema Único de Saúde como um conteúdo pontual? Por que o SUS, suas diretrizes, princípios e políticas públicas não são mais ensinados/aprendidos ao longo do curso? Cabe ainda ressaltar que, ao falarem de suas motivações para fazer o curso “Saúde, educação e política: práxis no SUS", querer saber mais sobre o sistema público de saúde brasileiro e sobre as políticas públicas de saúde foi o motivo mais referido pelos/as estudantes. Sinal de déficit nas disciplinas curriculares, de fragilidade/necessidade da grade curricular, justificando a grande procura pelo curso?

Os textos e vídeos selecionados para serem trabalhados no curso também demonstram a preocupação com a linguagem e com a aprendizagem significativa: os materiais acessíveis e discutidos em 'círculos de cultura' respeitavam os diferentes momentos de cada um/uma e permitiram que, na discussão, fossem problematizados os conteúdos. Como recurso para aproximar os sujeitos e provocar a problematização de determinadas situações, foram utilizadas também algumas dinâmicas que permitiram o aprofundamento no objeto de conhecimento com base em diferentes visões e estimularam também a atitude ativa das estudantes. 
Para fins de avaliação não só dos/as estudantes, mas do próprio processo educativo, ficou combinado, no primeiro dia de aula, que os/as participantes entregariam semanalmente narrativas de suas vivências no curso nas quais deveriam relatar e refletir sobre a experiência. Percebendo a dificuldade de alguns/algumas estudantes para se expressarem, refletirem e escreverem sobre aquilo que viviam, a cada semana as organizadoras indicavam uma questão condutora, da qual os/as estudantes poderiam partir para elaborar as narrativas.

A intencionalidade percebida nessa ação das organizadoras foi a de respeitar os limites dos/as estudantes e de propiciar que cada um/uma, à sua maneira, pudesse se manifestar. À medida que se escreve sobre a prática, ela é revisitada. Isso permite que se pense não só sobre ela, refletindo-se sobre como ela se desenvolveu, mas também nas modificações necessárias, percebidas nesse momento de reflexão e de elaboração das narrativas. Pois,

falar do dito não é apenas re-dizer o dito, mas reviver o vivido que gerou o dizer que agora, no tempo do redizer, de novo se diz. Redizer, falar do dito, por isso, envolve ouvir novamente o dito pelo outro sobre ou por causa do nosso dizer (Freire, 1992, p. 8).

A opção das organizadoras de elaborar questões semanais para os/as estudantes visa proporcionar segurança aos/às mesmos/as, tanto para aqueles/as que chegam à universidade e não estão habituados/as com esse tipo de escrita quanto para aqueles/as que já estão quase se formando, e também não costumam se expressar, refletir ou descrever a prática com sentimento, escrevendo livremente, sem formas padronizadas. No entanto, não foram sugeridas questões que desrespeitassem a historicidade e a capacidade dos/as estudantes ou que fossem limitadoras do pensar crítico. Pelo contrário, as questões propostas levavam à reflexão, pois não havia respostas certas para elas. Eis um exemplo: "Com o que foi visto hoje sobre o SUS e as políticas de saúde, o que podes relacionar com a tua vida (pessoal e profissional)?". Para responder essa questão, o/a estudante precisa estabelecer relações com seu cotidiano, com sua experiência, pensar sobre a sua prática social. A seguir, outro exemplo de questão que exige reflexão: “Um homem não se banhará no mesmo rio, pois o rio não será mais o mesmo e o homem também não". Essa reflexão surgiu como proposta de questão condutora ao final do círculo de cultura cujo como tema gerador foi a educação.

A dialogicidade como diretriz dessa prática educativa voltou-se para uma formação universitária que atendesse aos interesses da sociedade, de maneira que, enquanto estudantes e, depois, como profissionais, esses indivíduos possam se engajar ao lado do povo nas lutas por melhorias na atenção ao seu direito à saúde, pela justiça social e por avanços no Sistema 
Único de Saúde. Assim, o diálogo foi praticado em uma relação horizontal, na qual todos buscaram juntos ser mais, 'aprendendo a dizer a sua palavra'.

A educação bancária foi denunciada como prática antidialógica que atende aos interesses de alguns - uma prática alienada e alienadora que serve para manter as desigualdades nas condições de vida e de acesso a bens e serviços que são direitos de todo cidadão e cidadã. Em contrapartida, o diálogo foi anunciado, e pronunciado por todos/as, como um caminho para a formação universitária crítica, um caminho que interessa àqueles que sonham esperançosamente com uma sociedade justa e que buscam relações mais humanas, com a amorosidade imprescindível às lutas.

O diálogo em Freire (...) é condição sine qua non para os sujeitos abandonarem o estágio de domesticação e atingirem um processo de conscientização, superando a consciência ingênua ou intransitiva por um estágio de consciência essencial a uma educação voltada à responsabilidade política e social (Costa, 2008, p. 143).

É preciso que o exercício da autonomia, buscando manter a coerência entre discurso e prática, 'corporificar a palavra pelo exemplo' (Freire, 2007), leve à prática educativa libertadora e propicie o protagonismo dos sujeitos envolvidos. Pois como ensinar ao profissional que ele precisa assumir um papel de liderança, que tem de saber posicionar-se, saber exercitar a autonomia na sua prática, se no ensino da profissão os estudantes são castrados? $\mathrm{Ou}$ ainda, como podemos falar que é preciso respeitar o outro, estar com o outro, lutar pelos direitos, se a nossa prática é antidialógica e antidemocrática?

Dentro da academia, infelizmente não temos a oportunidade e/ou espaço para exercer a autonomia, ou seja, não temos a liberdade de pensar e agir guiados, apenas, por valores e crenças pessoais. A todo momento, somos treinados/adestrados a pensar, agir e ser aquilo que nos propusemos inconscientemente, sem questionarmos se é isso mesmo que viemos fazer aqui. Particularmente, [o curso "Saúde, educação e política: práxis no SUS"] é uma oportunidade de 'ser mais eu', de poder dizer que não sei e que vim aqui para aprender, sem ter medos de críticas. A atmosfera é de total aconchego. A socialização dos conhecimentos, experiências e ideias, o respeito ao próximo, a construção coletiva, o espírito empreendedor, são características marcantes presentes no contexto (E16, Narrativa).

A educação popular tem como eixo a conscientização que não é apenas a tomada de consciência, mas a transição da consciência comum/ingênua para a consciência reflexiva/crítica, e o aprofundamento dessa consciência crítica, que resulta em práxis social (Batista, 2007; Scocuglia, 2008). É pela politicidade assumida e pela intencionalidade transformadora que a educação popular é mediadora na transição da consciência. Essa educação coloca-se a 
favor de um modelo de sociedade justa, fraterna e humanitária, com relações verdadeiramente democráticas; a favor de um mundo que propicie a todos viverem a liberdade que têm e protagonizarem a sua história.

A conscientização por si só não resulta necessariamente em transformação social. Ela também não se dá no espontaneísmo e nem é programada para que o educando passe, rigorosamente, pelas etapas de seu processo de tomada de consciência: da transição da consciência comum/ingênua para a consciência reflexiva/crítica e, consequentemente, a transformação da realidade por meio de uma práxis revolucionária. Essas não são etapas rígidas. São mais uma forma de teorizar, de interpretar o processo, do que um método intransigente (Gadotti, 2001).

A tensão entre paciência e impaciência é outra característica importante da educação popular libertadora, pois a paciência sozinha pode levar à acomodação, à imobilização; já a impaciência pode levar à arrogância, ao ativismo. Assim, uma depende da outra (Freire, 1997).

A impaciência impede que determinadas situações sejam simplesmente impostas de forma incontestável e imutável. E a paciência não pode ser espera passiva, e sim ansiosa daqueles que buscam com esperança, pois estão conscientes do inacabamento da história e do seu próprio inacabamento. A esperança nas transformações e o amor às causas às quais os indivíduos se engajam é o que move aqueles que verdadeiramente acreditam que mudanças são necessárias e possíveis, que acreditam no inédito viável. No momento em que se deixa de crer nas transformações, deixa-se de lutar.

A esperança, a amorosidade, a paciência-impaciente com as quais os sujeitos engendram a concretização da práxis que intenciona contribuir com a formação universitária-social crítica proporcionaram a construção de espaços dialógicos para se pensar-agir a favor da saúde pública e de qualidade como direito de todos e todas.

Contudo, da mesma forma como foram experienciadas potencialidades nessa práxis educativa, também foram percebidas algumas fragilidades. A mudança na programação foi uma delas, pois, inicialmente o curso foi estruturado para propiciar maiores aprofundamentos nos conteúdos e mais vivências na realidade do SUS e no controle social da saúde, bem como uma aproximação com os movimentos sociais.

Identificamos dois motivos que levaram à mudança. O primeiro deles foi consequência da epidemia de gripe A em 2009, levando ao adiamento do início do segundo semestre letivo. Consequentemente, dado o encurtamento do tempo, houve uma concentração das atividades, e professores e estudantes tiveram de se adaptar ao ritmo posto. Em algumas disciplinas, por exemplo, foi necessário que os/as estudantes fizessem provas aos sábados. Não dispunham, portanto, de muito tempo livre para atividades extracurriculares. 
Outro motivo que pode ter provocado a mudança na programação está relacionado com o próprio andamento do curso. Foram previstas várias atividades para um mesmo encontro, e muitas vezes não foi possível cumprir o previsto, pois a metodologia fazia que todos/as participassem ativamente das discussões, e elas se prolongavam além do imaginado, extrapolando, por vezes, as três horas previstas para a duração dos encontros.

O descumprimento do cronograma inicialmente proposto não pode ser interpretado como uma fragilidade, mas a falta de aprofundamento de alguns aspectos e das vivências práticas sim. O curso foi mais teórico, mais voltado para provocações na formação dos/as estudantes, e isso se deve às condições que estavam postas e às próprias características das pessoas que constituíram a práxis. Essa condição não chegou a ocasionar o descumprimento dos objetivos propostos pelo curso, mas também impediu uma maior aproximação à realidade social do SUS e uma problematização mais intensa sobre aspectos do controle social no sistema de saúde brasileiro.

No encontro que teve como tema "Educação dialógica x educação bancária", pode ser percebido o esforço para manter a coerência na prática, pois estava previsto um grande número de atividades para abordar o conteúdo - a primeira delas, a discussão do texto Vaso vazio e vaso cheio, de autoria desconhecida. Depois, haveria uma apresentação de vídeo e provocações acerca da educação popular. Porém, só a discussão do texto, que tinha apenas duas páginas, durou mais de duas horas - praticamente todos/as os/as presentes participaram do debate, trazendo experiências e estabelecendo relações com seus cotidianos. Caso as organizadoras tentassem tolher a discussão, a sua prática seria contraditória, pois nesse momento os/as estudantes expunham situações em que se sentiam reprimidos/as na sala de aula, como no fato relatado por eles/as de que um professor havia dito: "Vocês precisam parar de perguntar, senão não vou vencer o conteúdo e aí vocês não vão aprender nada".

Como exemplo de flexibilização e de coerência teórico-metodológica, a discussão aconteceu livremente. Assim, enquanto os/as estudantes tinham coisas para dizer, as diziam, pois 'ensinar é ensinar a dizerem a sua palavra' (Freire, 2005). Sendo a educação uma ação humana, é impossível controlá-la metodicamente, prevê-la totalmente. Como afirmou $\mathrm{O} 3$ nesse mesmo encontro: "o conteúdo não tem que ser inimigo do professor". Assim, foi preciso adaptar o cronograma, tendo sido retomada, em outro encontro, a questão da educação popular e de suas relações com o setor saúde.

Outra fragilidade do curso foi a postura educativa de alguns/algumas estudantes, observada na organização e apresentação dos seminários e nas vivências que deveriam fazer. Após terem se dividido em quatro grupos, de forma que um grupo não ficasse com muitos/as estudantes do mesmo curso e série, foram orientados/as de que a forma de condução dos seminários 
seria de sua responsabilidade e que, no exercício da autonomia e da criatividade, poderiam valer-se de diferentes recursos à sua escolha. Foi dito que também poderiam trazer um/uma convidado/a com alguma experiência no assunto para participar, e que seria possível pedir o auxílio das organizadoras, caso tivessem necessidade de orientação. Os/as estudantes, de forma geral, tiveram dificuldades para se organizar e trabalhar em equipe: não utilizaram o tempo previsto durante o próprio curso para a organização do seminário e alguns grupos fizeram uma apresentação mais formal, privilegiando a leitura de slides, o que não permitiu a discussão e a participação de todos/as. Há de se considerar, no entanto, que participavam da atividade estudantes das séries iniciais dos cursos de graduação, sem experiência de apresentação de trabalhos, organização de atividades, trabalho em equipe e responsabilidade de tomadas de decisão. Nos seminários e nas vivências, os/as estudantes tiveram dificuldade em lidar com a autogestão e com a liberdade de forma; alguns/algumas não conseguiram preparar-se e dedicar tempo para encontrar outros meios de apresentação que não a apresentação de slides. Contudo, com as atividades reflexivas propostas, conseguiram avaliar suas condutas e refletir sobre as dificuldades:

A visita não pôde ser realizada devido à minha falta de organização, pois deveria ter observado antes que, para entrevistar ou falar com qualquer enfermeiro ou agente comunitário, teria que ter autorização (El, Reflexão final).

Se tivéssemos feito o trabalho em uma aula e apresentando, em um segundo momento, cartazes ou uma dramatização seria mais rico. (...) Não consigo trabalhar com improvisação, prefiro o planejamento e no máximo, se necessário, criatividade (E4, 14 nov. 2009).

Na primeira fala, a estudante refere-se à atividade prática que seu grupo tinha de organizar. Por desconhecer a rotina do serviço, ela não conseguiu agendar a tempo a visita a uma unidade de saúde para observação e a entrevista com um trabalhador. Assim, o grupo não conseguiu realizar a atividade; uma das integrantes do grupo, que já estava em prática em uma unidade de saúde do município, realizou a atividade sozinha, colhendo dados para o grupo. Na segunda fala, a estudante reflete sobre as dificuldades enfrentadas na realização do seminário e, mesmo dizendo-se satisfeita com o resultado, acredita que ele poderia ter sido melhor se tivessem trabalhado com maior organização no grupo.

Um fator importante a ser considerado no que diz respeito a essa questão é a natureza da instância educativa. Sendo o curso uma atividade não curricular e não remunerada, os/as estudantes podem ter priorizado a elaboração de atividades das disciplinas curriculares ou os projetos financiados 
em que tinham de cumprir efetividade, sob pena de não receberem bolsa de estudos ou mesmo certificado. Isso não justifica as atitudes de descompromisso observadas, pois os/as estudantes se propuseram a fazer o curso mesmo sabendo da carga horária e das atividades propostas, mas leva a alguns questionamentos sobre quais os reais motivos desse comportamento e o que é necessário para que participem mais ativamente.

É preciso fazer um esforço para compreender que os/as estudantes estão habituados/as com uma 'formatação acadêmica' que padroniza atitudes e mercantiliza a participação de estudantes na lógica capitalista da ciência. Ou seja, precisam render, produzir mais e mais, o que pode levar à alienação do processo de produção do conhecimento, a um esvaziamento do sentido pedagógico.

Apesar dos avanços políticos no caminho da democracia, ainda não se pode dizer que vivemos em condições que propiciem a participação. A educação, seja ela formal, não formal ou informal, ainda carrega o peso de uma era de submissão, silenciamento e hierarquização das relações, e a educação dialógica ainda é minoritária nas instâncias educativas (Costa, 2008).

Outra fragilidade encontrada no curso foi a dificuldade em elaborar e entregar as narrativas. Quais os motivos para isso? O que levou à demora e mesmo à não entrega das narrativas? Falta de tempo ou de hábito, desinteresse, dificuldade de compreensão? Por não serem ameaçados/as com a suspensão de bolsa ou de certificados? Por discordarem da proposta? Pelo fato de o curso não ser uma atividade curricular? Talvez a causa da dificuldade de cumprir com a elaboração das narrativas tenha sido um somatório de todas essas hipóteses - provavelmente cada um/uma dos/as estudantes tenha uma ou mais razões diferentes para não cumprirem o acordado.

Mesmo tendo sido explicado no início do curso a intencionalidade das narrativas, ficando combinado que semanalmente entregariam suas reflexões, e sendo retomadas as explicações iniciais ao longo do curso diante das dificuldades percebidas, poucos/as foram os/as estudantes que entregaram com regularidade seus registros. Daqueles/as que entregavam, alguns/algumas tinham dificuldades em se colocar no texto, escreviam superficialmente sobre a sua participação, sem estabelecerem relações, sem pensar a prática. Já a reflexão final deixou de ser realizada por apenas dois/duas estudantes, e todos/as que entregaram conseguiram se expressar, realmente revisitando o dito e o vivido no momento de pensar e escrever sobre a vivência. Conforme expressa a estudante:

Quando você acha que tem todas as respostas, o curso vem e muda todas as perguntas. Acredito que esta frase resume o propósito do curso e o impacto que teve em minha vida (El, Reflexão final). 
As coordenadoras explicaram várias vezes que o propósito das narrativas era o de auxiliar na reflexão sobre a prática individual. Também eram importantes para a organização do curso, pois podiam trazer contribuições para o mesmo e para as suas próximas edições. Em relação a esse ponto, revela-se uma incoerência na atitude. Embora tenham sido experienciadas relações de horizontalidade entre estudantes e coordenadoras - foi solicitado aos/às estudantes apenas que fizessem as narrativas - , as coordenadoras não realizaram essa atividade de reflexão, de contribuição para a prática individual e coletiva.

A coerência é uma virtude que depende do exercício de outras virtudes, como a paciência, a decisão e a humildade. Se na reflexão - tão fundamental - sobre a prática, educadoras e educadores percebem-se incoerentes, podem optar por romper com o que está posto. Portanto, a coerência não é imobilizadora: não é porque uma vez se pensou/agiu de determinada forma que, para se manter coerente, é preciso pensar/agir sempre da mesma forma. As educadoras e os educadores, percebendo falhas na própria prática pedagógica, devem optar por transformá-la, agindo para transpor e superar alguns paradigmas, para mudar a forma de pensar/agir e, com isso, buscar a coerência, que, afinal, é impossível de ser experimentada plenamente (Freire, 1992 e 1997).

A tensão entre paciência e impaciência faz-se necessária para compreender que as formas de enfrentamento das diferentes situações são historicizadas - influenciadas pelas experiências já vividas e pela cultura -, e que as mudanças são gradativas. Não se trata de aceitar e de se adaptar à situação, mas de compreender, impacientemente, tencionando a favor da mudança. Portanto, é preciso, no desenvolvimento das atividades futuras, que a metodologia adotada seja mantida, ainda que possa ser adaptada em alguns pontos a fim de atender às especificidades de outros grupos, permanecendo, porém, como um espaço que se abre à participação e à construção coletiva, e que, portanto, faz-se democrático, processo que buscou, com êxito, incitar o exercício da criatividade e da liberdade.

A existência presume correr riscos, reconhecer e estar aberto às novidades (Freire, 2006). Na prática educativa, não se foge a essa condição; nela se correm riscos, como o de tender mais para a paciência ou mais para a impaciência ou o de não reconhecer que a autoridade não fere, necessariamente, a liberdade. Corre-se também o risco de ser incoerente. E o medo de correr riscos pode imobilizar, pode fechar possibilidades de conhecer e percorrer novos caminhos.

É vivendo, não importa se com deslizes, com incoerências, mas disposto a superálos, a humildade, a amorosidade, a coragem, a tolerância, a competência, a capacidade de decidir, a segurança, a eticidade, a justiça, a tensão entre paciência e 
impaciência, a parcimônia verbal, que contribuo para criar, para forjar a escola feliz, a escola alegre. A escola que é aventura, que marcha, que não tem medo do risco, por isso que recusa o imobilismo. A escola em que se pensa, em que se atua, em que se cria, em que se fala, em que se ama, se adivinha, a escola que apaixonadamente diz sim à vida. E não a escola que emudece e me emudece (Freire, 1997, p. 42).

Foi correndo riscos que os/as participantes (organizadoras, estudantes e colaboradoras) materializaram a prática aqui analisada, possibilitando a concretização do sonho daqueles/as que idealizaram o curso (antes uma disciplina curricular) a tornar-se uma práxis fortemente fincada na educação popular, dialógica e problematizadora fundamentada por Paulo Freire. E foi também com gosto pelo novo e pela aventura, permitindo-se tentar com rigorosidade metódica; foi com querer bem à prática e uns aos outros, e com a esperança de que é possível a formação universitária em ambiente amoroso e com uma educação conscientizadora e libertadora, vinculada às lutas sociais, como as da saúde pública de qualidade, de melhores condições de vida, a luta por um SUS para todos que atenda às reais necessidades dos cidadãos.

\section{Conclusões}

O desenvolvimento do curso "Saúde, educação e política: práxis no SUS" não poderia promover sozinho a transformação da práxis dos sujeitos, e nem mesmo uma transformação da formação universitário-social. Ele é apenas parte de um processo de formação que necessariamente é permanente. Como a educação é um ato político, pois é uma forma de intervenção no mundo, nela assumimos, implícita ou explicitamente, a ideologia que move a nossa prática. Por isso o adjetivo 'popular' na educação reforça e evidencia a diretividade e a intencionalidade da práxis, tornando claro a favor do que e de quem estamos.

Para a transformação da realidade na saúde pública, é preciso que se assuma explicitamente a politicidade da formação para a saúde. Ou buscamos o desvelamento e a transformação 'das causas das causas' das doenças, ou naturalizamos as condições precárias e injustas em que vive a maioria dos brasileiros e das brasileiras. A educação popular não é apenas uma educação para o povo, mas é, sobretudo, um caminho para a conscientização, uma prática na qual se assume que estamos a favor do povo, contra todas as formas de injustiça e desigualdade, e não a favor da alienação e da manutenção das situações desumanas em que vive grande parte da população. A educação popular, portanto, pode e deve ser assumida também na universidade 
para a formação de profissionais que virão a atender os usuários do SUS, possibilitando que os estudantes, no caminho do aprender a conhecer, a fazer, a ser e a viver junto, engajem-se na luta por condições mais justas de vida, a fim de que a população tenha direito à promoção da saúde, à recuperação e ao tratamento de doenças. Enfim, para que ela tenha melhor qualidade de vida.

Os indivíduos que edificaram o curso não poderiam ser fatalistas nem coniventes com os fracassos do aprender-ensinar e do saber-fazer na saúde pública. Não poderiam reproduzir o discurso de muitos de que o SUS é um fracasso, que o sistema público de saúde não funciona e que não há nada a fazer, cruzando os braços diante dessa denúncia. Isso seria colocar-se a favor da manutenção de uma situação que desrespeita o direito à saúde. Tampouco poderiam dizer que não há diversos problemas a serem enfrentados na realidade do sistema de saúde, pois isso seria enganoso.

É preciso olhar para a realidade com criticidade, mas também com esperança. A formação em saúde tem de problematizar tanto a realidade social quanto a realidade de funcionamento do SUS. Tem de trabalhar a favor da concretização do SUS não como um ideal utópico inatingível, mas como o inédito viável, o sonho possível de um país em que todos e todas tenham acesso aos serviços de saúde com qualidade, em que tenham a possibilidade de um viver saudável, um viver digno.

Essa prática educativa não foi investigada para que se descortinassem respostas que viessem a atender as questões ainda latentes sobre a formação para o SUS, nem transmitir, de forma bancária, conceitos e aplicabilidades da educação popular no âmbito da saúde. Constitui, na verdade, uma maneira de refletir sobre a formação por meio de elementos que caracterizam a educação popular. Com isso, pretende-se contribuir com as experiências e também com o arcabouço teórico necessário para a sustentação da prática - afinal, teorizar sobre a educação popular é tão importante como praticá-la, pois uma práxis só é práxis quando materializada (Batista, 2007).

O grande número de inscrições de estudantes de diferentes cursos de graduação, a participação efetiva e a dedicação que os/as estudantes investiram nessa prática educativa indicam a relevância de propostas como essas para a formação do ponto de vista dos/as estudantes. É preciso, portanto, que sejam criadas outras oportunidades e também que se dê continuidade a essa experiência.

No corrente ano, acontece a terceira edição do curso "Saúde, educação e política: práxis no SUS", servindo a experiência anterior, tanto seus aspectos positivos quanto os negativos, como referência para as organizadoras (entre as quais agora estão incluídas estudantes que participaram anteriormente do curso). Não foi abandonada a ideia de propor essa atividade como uma disciplina do currículo. 


\section{Notas}

${ }^{1}$ Enfermeira. Mestre em Enfermagem pela Universidade Federal do Rio Grande (Furg). $<$ acostajuliana@gmail.com>

Correspondência: Rua Manoel Pereira de Almeida, nº 717, Bloco 2, ap. 103, CEP 96200-440, Rio Grande, Rio Grande do Sul, Brasil.

2 Professora do Programa de Pós-Graduação em Enfermagem da Universidade Federal do Rio Grande (FURG), Rio Grande, Rio Grande do Sul, Brasil. Doutora em Enfermagem pela Universidade Federal de Santa Catarina (UFSC). < bethcestari@yahoo.com.br>

\section{Referências}

ANDRÉ, Marli Elisa Dalmazo. Estudo de caso em pesquisa e avaliação educacional. Brasília: Liber, 2008. (Série Pesquisa, 13).

BATISTA, Aline Maria de Melo. Práxis, consciência de práxis e educação popular: algumas reflexões sobre suas conexões. Educação e Filosofia, Uberlândia, v. 21, n. 42, p. 169192, jul.-dez. 2007.

BRASIL. Ministério da Saúde. Caminhos para a mudança da formação e desenvolvimento dos profissionais de saúde: diretrizes da ação política para assegurar educação permanente no SUS. Brasília: Ministério da Saúde, 2003.

CECCIM, Ricardo B. Pacientes impacientes. In: BRASIL. Ministério da Saúde. Secretaria de Gestão Estratégica e Participativa. Departamento de Apoio à Gestão Participativa. Caderno de educação popular e saúde. Brasília: Ministério da Saúde, 2007. (Série B, Textos Básicos de Saúde).

COSTA, Antônio Roberto da. Educação popular e diálogo: precisa a educação (popular) ser dialógica(?). In: ROSAS, Agostinho da Silva; MELO NETO, José Francisco de (org.). Educação popular: enunciados teóricos. v. 2. João Pessoa: Editora Universitária da UFPB, 2008.
FLICK, Uwe. Métodos de pesquisa. Introdução à pesquisa qualitativa. 3. ed. Porto Alegre: Artmed, 2009.

FREIRE, Paulo. Pedagogia da autonomia: saberes necessários à prática educativa. 34. ed. São Paulo: Paz e Terra, 2006.

Pedagogia da esperança: um reencontro com a pedagogia do oprimido. 10. ed. Rio de Janeiro: Paz e Terra, 1992.

Pedagogia do oprimido. 45. ed. Rio de Janeiro: Paz e Terra, 2005.

Professora sim, tia não. Cartas a quem ousa ensinar. São Paulo: Olho D'Água, 1997.

FREIRE, Paulo; SHOR, Ira. Medo e ousadia: o cotidiano do educador. 5. ed. Rio de Janeiro: Paz e Terra, 1987.

GADOTTI, Moacir. Educação e poder: introdução à pedagogia do conflito. 12. ed. São Paulo: Cortez, 2001.

LÜDKE, Menga; ANDRÉ, Marli. Pesquisa em educação: abordagens qualitativas. São Paulo: EPU, 1986. 
MINAYO, Maria Cecília de Souza. O desafio do conhecimento. Pesquisa qualitativa em saúde. 8. ed. São Paulo: Hucitec, 2004.

PAIM, Jairnilson. O que é o SUS? Rio de Janeiro: Editora Fiocruz, 2009.

SCOCUGLIA, Afonso Celso. Paulo Freire e a 'conscientização': entre a modernidade e a pós-modernidade progressista. Revista de Educação de Jovens e Adultos, v. 2, p. 3, 2008.

TURATO, Egberto Ribeiro. Tratado da metodologia da pesquisa clínico-qualitativa. Petrópolis: Vozes, 2003.

Recebido em 16/06/2010

Aprovado em 20/06/2011 